\title{
A Heuristic Approach to Measure Contribution of Foreign Trade to Growth
}

\author{
Azman Hassan ${ }^{\mathrm{a}}$ \\ M. Yusof Saari ${ }^{b}$ \\ Nur Adilah Hamidc \\ Chakrin Utit ${ }^{d}$ \\ Ibrahim Kabiru Maji \\ Universiti Putra Malaysia
}

\begin{abstract}
Contribution of final demand components to gross domestic product (GDP) is often measured by a simple aggregated national accounting identity. Under this conventional approach, the contribution of exports is subtracted from imports to compute the contribution of net exports but it fails to split the imported intermediate and final use that is embodied in each domestic final demand. The so-called importadjusted approach is considered to be an ideal approach to measure the contribution of each final demand component to GDP. This approach splits imported intermediate and final use for each final demand component instead of accumulating all of them in the export component. This paper provides a heuristic approach for the application of import-adjusted approach to time-series data. We show that given a benchmark inputoutput table and provided with the annual trade statistics, the bias in measuring the contribution of domestic demand and foreign trade can be reduced. More importantly, we have provided a practical approach that does not only reduce man-hours required for database development but also obtain satisfactory findings. Results verify that the conventional approach tends to overestimate the contribution of domestic demands and underestimate the contribution of net trade to GDP.
\end{abstract}

Keywords: Gross domestic product (GDP), import-adjusted approach, input-output, foreign trade

JEL classification: C67, D57, 021

a Department of Economics, Faculty of Economics and Management, Universiti Putra Malaysia, 43400 UPM Serdang, Selangor, Malaysia. Email: azmanhs@upm.edu.my

b Department of Economics, Faculty of Economics and Management, Universiti Putra Malaysia, 43400 UPM Serdang, Selangor, Malaysia. The author is also affiliated to the Institute of Agricultural and Food Policy Studies of the same university, and Khazanah Research Institute, Malaysia. Email: yusofsaari_upm@upm. edu.my (Corresponding author)

c Department of Economics, Faculty of Economics and Management, Universiti Putra Malaysia, 43400 UPM Serdang, Selangor, Malaysia. Email: nuradilahhamid@gmail.com

d Institute of Agricultural and Food Policy Studies, Universiti Putra Malaysia, 43400 UPM Serdang, Selangor, Malaysia. Email: chakrin_utit@upm.edu.my or uchakrin@gmail.com

e Department of Economics, Faculty of Economics and Management, Universiti Putra Malaysia, 43400 UPM Serdang, Selangor, Malaysia. Email: keibimaji@gmail.com

Acknowledgement: This paper is one of the output from the research initiative "Dualistic Structures and Drivers of the Malaysian Economy" conducted by the Khazanah Research Institute in collaboration with Universiti Putra Malaysia. The information and views set out in this paper are those of the authors and do not necessarily reflect the official opinion of Khazanah Research Institute. Neither the Khazanah Research Institute and connected bodies nor any person acting on their behalf may be held responsible for the use of the information contained therein.

Article Info: Received 18 October 2016; Revised 16 October 2017; Accepted 7 March 2018 


\section{Introduction}

At the macro level, the contribution of foreign trade to the domestic economy is commonly measured by using the conventional accounting identity of gross domestic product (GDP). Under this conventional approach, changes in GDP are separated according to changes in different types of final demand expenditures which include private consumption, government consumption, investment (a combination of gross fixed capital formation and change in stock) and exports. The contribution of each final demand expenditure component on the GDP identifies the sources of demandside growth. This conventional approach is simplistic and often leads to interpretation bias regarding the actual contribution of foreign trade on the domestic economy. It is important to resolve this measurement issue but has received little attention in the literature (see for example, Kranendonk \& Verbruggen, 2005; Bank Negara Malaysia, 2013).

Under conventional GDP accounting, the contribution of exports is subtracted from imports to compute the contribution of net exports but it fails to split the import contents in domestic final demands. There are two types of imports contained in each consumption good made by domestic final demand, that is, imported final use goods and imported intermediate goods. Imported final use goods are for direct consumption while imported intermediate goods are for indirect consumption as they are required to satisfy domestically produced goods. The conventional approach ignores these two imports that are consumed directly and indirectly by domestic final demand components; instead, they are accounted under the external trade component (see for example, Department of Statistics Malaysia, 2014a). It should be stressed that different final demand components have different consumption patterns on domestically produced goods which in turn affect differently the import contents. Because of this limitation, it is likely that the conventional approach in GDP accounting overstates the contribution of domestic final demand and underestimates the actual contribution of foreign trade (net exports) to the domestic economy.

For more accurate estimation, the consumption on imported intermediate and final use goods by each final demand component should be attributed individually and this can be achieved consistently through an input-output analysis (see for example, Bank Negara Malaysia, 2013). Input-output analysis is modelled based on a benchmark input-output table. However, the usefulness of the analysis is still hampered by the long delay with which it tends to appear. For example, the input-output table in Malaysia is published once for every five years while final demand aggregate data are available annually with a lag. In this paper, we introduce a heuristic approach in measuring the contribution of foreign trade on the Malaysian economy. We show that given a benchmark input-output table and provided with the annual trade statistics, the bias in interpreting the contribution of domestic final demand and foreign trade on the Malaysian economy can be reduced. Methodologies that we develop may not guarantee to be optimal or perfect but it is practical and sufficient to measure the actual contribution of foreign trade.

This paper is structured into five sections. Section 2 explains the bias in interpreting the contribution of foreign trade under the conventional approach. Section 3 develops 
a practical approach where the bias in measuring the contribution of foreign trade can be reduced. Section 4 discusses the major findings obtained from the analysis. Finally, Section 5 provides concluding remarks.

\section{Limitation of the Conventional Approach}

Final use of goods and services in an economy takes in two forms: (i) domestic demand which consists of private consumption, government consumption and investment (a combination of gross fixed capital formation and change in inventory), and (ii) external (foreign) demand or simply exports. Imports of goods and services represent leakages to the domestic economy because they are not produced in the domestic economy and thus no value added has been created. Imports are consumed directly for final use and indirectly as raw materials for the production of domestic goods and services. To measure the growth in GDP, imported final use and intermediate goods must be subtracted from each component of final demand.

Figure 1a shows the contribution of each final demand component to GDP that is measured under the conventional approach while Figure $1 \mathrm{~b}$ presents the measure under the so-called import-adjusted approach. Under the conventional approach, imported final use and intermediate goods consumed directly and indirectly by the final demand components are attributed to the external demand to obtain net exports. In Malaysia, the reported expenditures by domestic final demands (i.e., private consumption, government consumption and investment) in the national accounts include both final consumption on domestically produced and on imported goods and services. However, when measuring the contribution of each final demand component to the

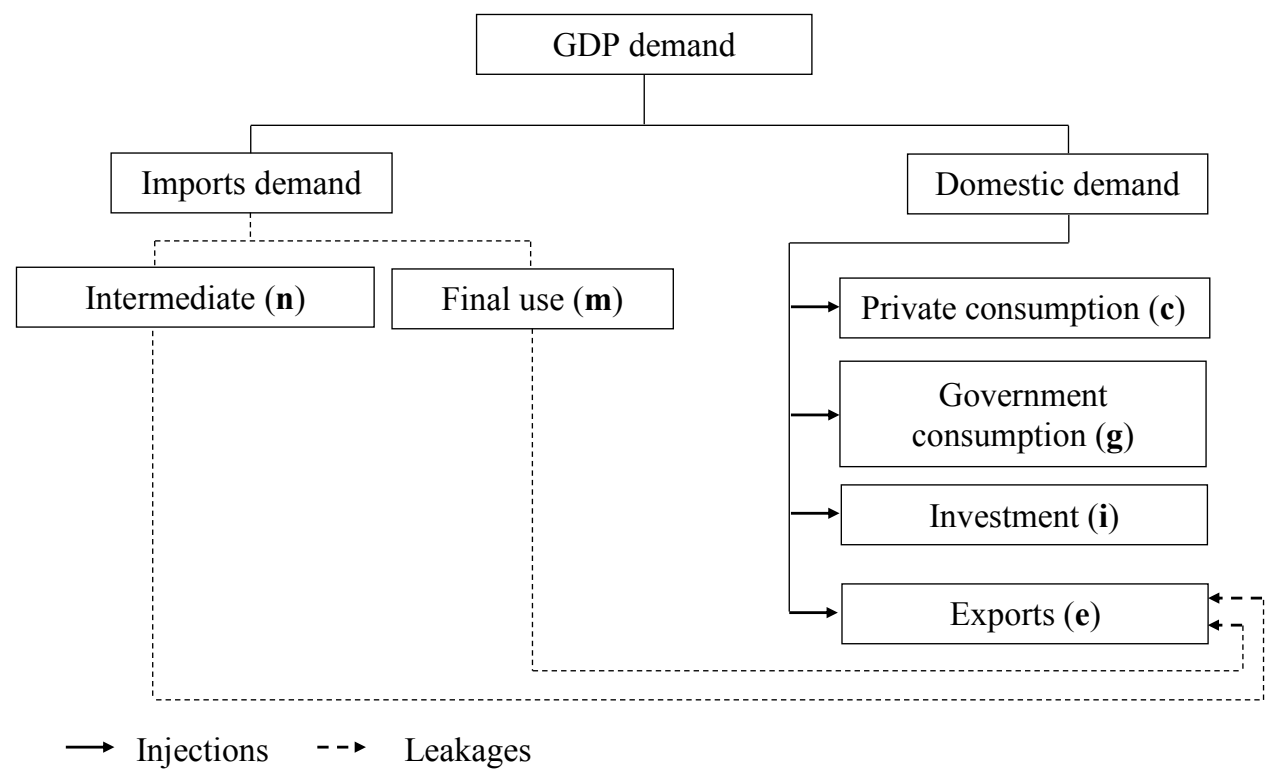

Figure 1a. Accounting GDP under conventional approach 


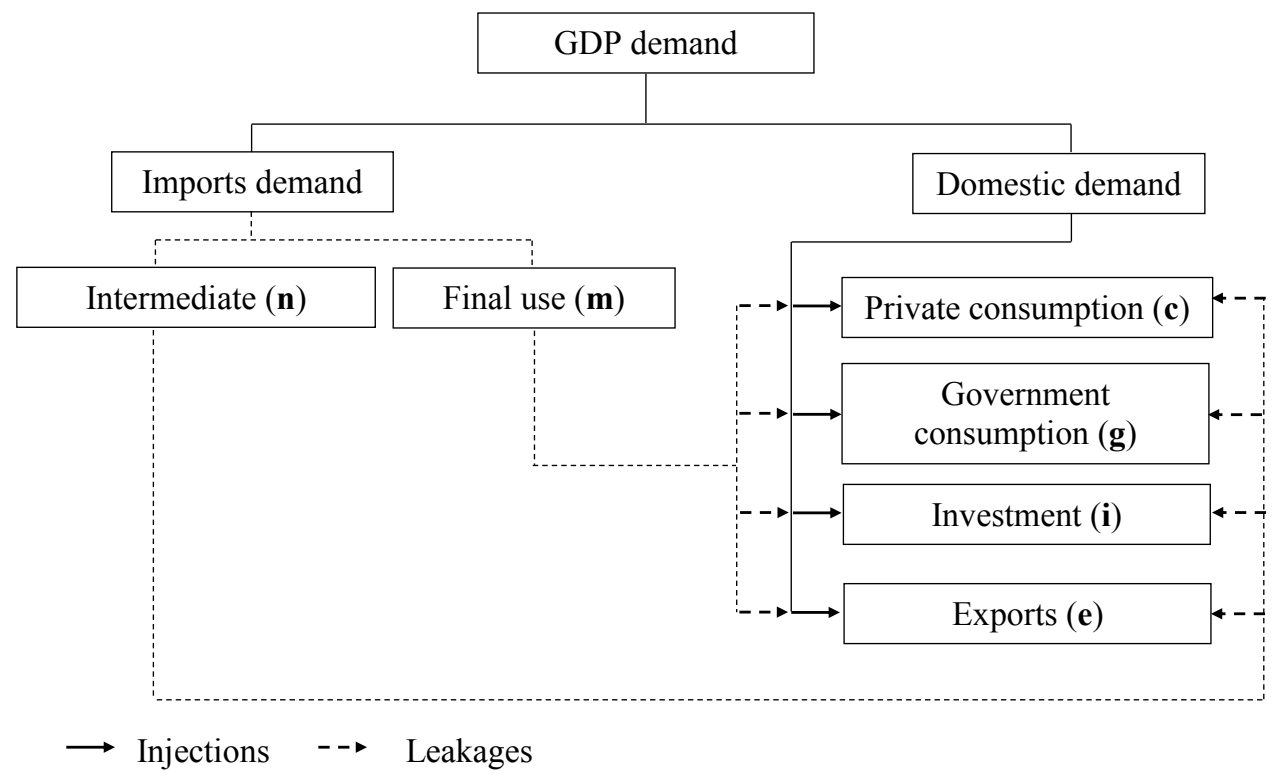

Figure 1b. Accounting GDP under import-adjusted approach

GDP, all final consumption on imported goods and services are attributed to the balance of goods and services or net exports (see Department of Statistics Malaysia, 2014a).

The conventional approach is economically deceptive because it ignores the link between the different components of demand and import requirements. Let us consider a hypothetical case where private consumption rises but this increment in consumption consists solely of imported goods (thus no value added created in the domestic economy). Yet, the conventional approach indicates an increase in the contribution of private consumption, which is equivalent to the decline in the net exports (because imported goods are attributed to external demand). For a more accurate approach, it would be preferable to attribute the rise in imports to the private consumption component since that is what gave rise to it. In that case, the contribution of private consumption and exports to the growth would change, better reflecting the economic reality of the relative contribution of each final demand component. This accurate approach is represented by the import-adjusted approach in Figure 1b. The import-adjusted method is considered to be the ideal approach to measure the contribution of each final demand to GDP because it splits imported intermediate and final use for each demand component instead of accumulating them all in the trade component.

Now let us illustrate the differences between these two approaches by taking the input-output table for 2005 as an example. Table 1 shows the aggregated version of 2005 input-output table for Malaysia, expressed in RM (Ringgit Malaysia) billion. In this input-output table, there are five aggregated sectors: agriculture, mining and quarrying, manufacturing, construction and services. Four final demand categories are 


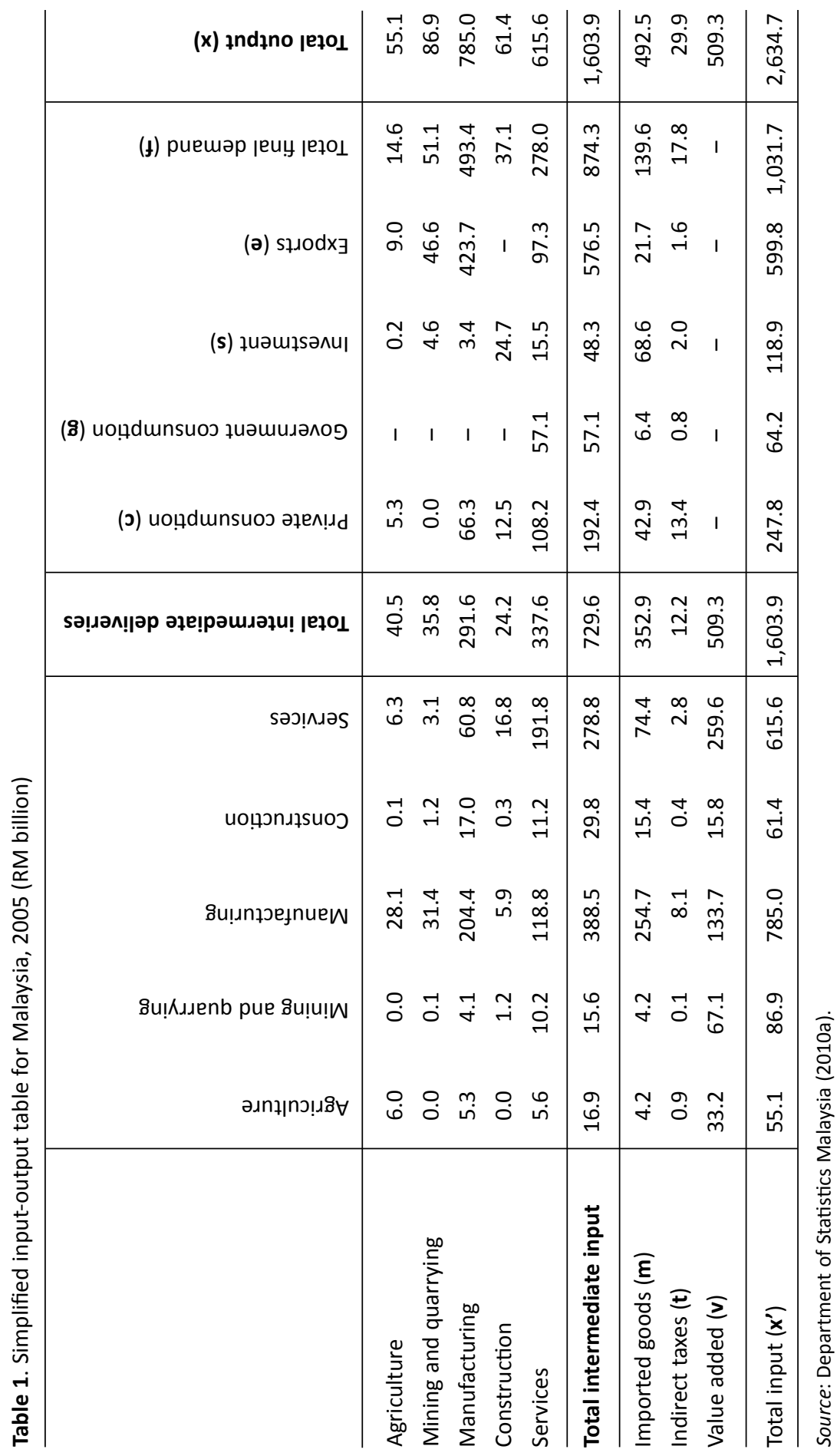


distinguished - private consumption (c), government consumption (g), investment (s) which consists of gross fixed capital formation and change in stock and exports (e). There are three primary input categories available - imported goods ( $\mathbf{m})$, indirect tax $(\mathbf{t})$ and value added $(\mathbf{v})$. In the input-output table, row $(i)$ indicates the intermediate and primary inputs purchased by each sector, while column $(j)$ shows sales of output to other sectors as intermediate deliveries and final demands.

The relationship between the sectors can be represented by the following expressions. ${ }^{1}$

$$
\mathbf{x}=\mathbf{Z i}+(\mathbf{c}+\mathbf{g}+\mathbf{s}+\mathbf{e})=\mathbf{Z i}+\mathbf{f}
$$

where $\mathbf{x}$ is the vector for gross output, $\mathbf{Z} \mathbf{i}$ is the summation vector matrix of intermediate deliveries and $\mathbf{f}$ is the vector for final demand - private consumption (c), government consumption (g), investment (s) and exports (e). Summing across the columns, the total gross output throughout the economy, $\mathbf{x}$ can be found in equation (1). The same value of input (since $\mathbf{x}^{\prime}=\mathbf{x}$ ) can be found by summing across the rows, as represented by equation (2).

$$
\mathbf{x}^{\prime}=\mathbf{i}^{\prime} \mathbf{Z}+\mathbf{m}+\mathbf{t}+\mathbf{v}
$$

The vector $\mathbf{m}$ gives the imported commodities, $\mathbf{t}$ shows the indirect tax and $\mathbf{v}$ gives the value added. Equations (1) and (2) are simply two alternative ways of summing all the elements in the table.

Based on transaction flows in Table 1, we summarise the contribution of each final demand component under the conventional approach and import-adjusted approach in Table 2. All the figures are taken directly from Table 1. Both approaches provide similar findings for the total GDP in 2005 at RM539.2 billion. However, the percentage contribution of each final demand component to the total GDP is greatly different. For example, the contribution of exports to GDP under the conventional approach is 20 percent while under the import-adjusted approach the contribution is 61 percent. For domestic demand, the conventional approach tends to overestimate its contribution to total GDP. For example, the contribution of private consumption to GDP is only 25 percent under the import-adjusted approach compared to 46 percent under the conventional approach.

The differences in the outcomes between these two approaches are due to the treatment of imports. As illustrated in Figure 1a, the conventional approach accumulates all imported final use and intermediate goods to the trade component. According to Table 1, the contribution of exports is derived by subtracting total exports (RM599.8 billion) with total imported final use (RM139.6 billion) and with total imported intermediate goods (RM352.9 billion). Under the import-adjusted approach, the consumption on imported final use and intermediate goods is removed for each

\footnotetext{
1 For clarity, matrices are indicated by bold, upright capital letters; vectors by bold, upright lower case letters, and scalar by italicised lower case letters. Vectors are columns by definition, so that row vectors are obtained by transposition, indicated by a prime (e.g. $\left.\mathbf{X}^{\prime}\right)$. A diagonal matrix with the elements of vector $\mathrm{x}$ on its main diagonal and all other entries equal to zero are indicated by a circumflex (e.g. $\hat{\mathbf{X}}$ ). A summation vector is represented by $\mathbf{i}$.
} 
Table 2. Contribution of final demand to GDP in 2005 (RM billion)

\begin{tabular}{lrrrrrr}
\hline & & $\begin{array}{c}\text { Private } \\
\text { consumption }\end{array}$ & $\begin{array}{r}\text { Government } \\
\text { consumption }\end{array}$ & $\begin{array}{r}\text { Invest- } \\
\text { ment }\end{array}$ & Exports & Total \\
\hline A. Conventional approach & & & & & & \\
Domestic consumption & $(1)$ & 192.4 & 57.1 & 48.3 & 576.5 & 874.3 \\
Imported final use & $(2)$ & 42.9 & 6.4 & 68.6 & 21.7 & 139.6 \\
Imported intermediate & $(3)$ & 0.0 & 0.0 & 0.0 & 0.0 & 352.9 \\
Indirect taxes & $(4)$ & 13.4 & 0.8 & 2.0 & 1.6 & 17.8 \\
Total consumption & $(5)$ & 248.7 & 64.2 & 118.9 & 599.8 & $1,031.7$ \\
Contribution to GDP & $\mathbf{( 6 )}$ & $\mathbf{2 4 8 . 7}$ & $\mathbf{6 4 . 2}$ & $\mathbf{1 1 8 . 9}$ & $\mathbf{1 0 7 . 3}$ & $\mathbf{5 3 9 . 2}$ \\
& & $\mathbf{( 4 6 \% )}$ & $\mathbf{( 1 2 \% )}$ & $\mathbf{( 2 2 \% )}$ & $\mathbf{( 2 0 \% )}$ & $\mathbf{( 1 0 0 \% )}$ \\
B. Import-adjusted approach & & & & & & \\
Domestic consumption & $(7)$ & 192.4 & 57.1 & 48.3 & 576.5 & 874.3 \\
Imported final use & $(8)$ & 42.9 & 6.4 & 68.6 & 21.7 & 139.6 \\
Imported intermediate & $(9)$ & 69.8 & 15.4 & 17.5 & 250.2 & 352.9 \\
Indirect taxes & $(10)$ & 13.4 & 0.8 & 2.0 & 1.6 & 17.8 \\
Total consumption & $(11)$ & 248.7 & 64.2 & 118.9 & 599.8 & $1,031.7$ \\
Contribution to GDP & $(\mathbf{1 2 )}$ & $\mathbf{1 3 6 . 1}$ & $\mathbf{4 2 . 4}$ & $\mathbf{3 2 . 8}$ & $\mathbf{3 2 7 . 9}$ & $\mathbf{5 3 9 . 2}$ \\
& & $\mathbf{( 2 5 \% )}$ & $\mathbf{( 8 \% )}$ & $\mathbf{( 6 \% )}$ & $\mathbf{( 6 1 \% )}$ & $\mathbf{( 1 0 0 \% )}$ \\
\hline
\end{tabular}

Note: Figures in parentheses express percentage contribution of each final demand component to total GDP. Source: Calculated from Table 1.

final demand component. Consumption on imported final use goods by each final demand component can be obtained directly from the input-output table. It should be further emphasised that the imported intermediate goods are the indirect consumption that is required to satisfy the consumption made by domestic demands for domestically produced goods. In the input-output table, imported intermediate goods are formed in a single row vector and no distinction is made between import requirements for various final demand components. To estimate the imported intermediate contents in each final demand, the following equations are used.

Treating the intermediate deliveries as an endogenous component and final demand as an exogenous component, (1) can be transformed into a standard inputoutput model as follows:

$$
\mathbf{x}=\mathbf{A x}+(\mathbf{c}+\mathbf{g}+\mathbf{s}+\mathbf{e})=\mathbf{A x}+\mathbf{f}
$$

where $\mathbf{A}\left(\mathbf{A}=\mathbf{Z} \hat{\mathbf{x}}^{-1}\right)$ is known as the input-output coefficient. The input-output coefficients show the amount of inputs that a sector purchased from other sectors and from primary input suppliers per unit of its own output. Solving for $\mathbf{x}$, we obtain total production delivered to final demand:

$$
\mathbf{X}=(\mathbf{I}-\mathbf{A})^{-1} \mathbf{c}+\mathbf{g}+\mathbf{s}+\mathbf{e}=(\mathbf{I}-\mathbf{A})^{-1} \mathbf{f}
$$

where $\mathbf{I}$ is the identity matrix, and $(\mathbf{I}-\mathbf{A})^{-1}$ is known as the Leontief inverse matrix. The Leontief inverse matrix represents the total production every sector must generate to 
satisfy the final demand. In other words, the coefficients denote the amount by which sector $i$ must change its production level to satisfy an increase of one unit in the final demand from sector $j$.

Next, let us introduce a vector of import coefficient $\mathbf{h}$, which is derived by dividing the amount of intermediate imports of the $j$ th sector by total input to that sector $x_{j}$. In matrix notation, $\mathbf{h}$ becomes:

$$
\mathbf{h}=\hat{\mathbf{x}}^{-1} \mathbf{m}
$$

Each element of import coefficient indicates consumption of imported intermediate goods per unit produced of output for each sector. Introducing (5) into (4), we obtain the amount of imported intermediate goods $(m)$ that is used to produce output for final demand components.

$$
\mathbf{m}=\hat{\mathbf{h}}(\mathbf{I}-\mathbf{A})^{-1} \mathbf{c}+\mathbf{g}+\mathbf{s}+\mathbf{e}=\hat{\mathbf{h}}(\mathbf{I}-\mathbf{A})^{-1} \mathbf{f}
$$

where $\hat{\mathbf{h}}$ is the import coefficient that is expressed in the form of a diagonal matrix. Results for the estimation are given in row (9) of Table 2. Under the import-adjusted approach, the consumption on imported final use and intermediate goods is subtracted directly from the total demand in each category. For example, the total demand for private consumption is RM136.1 billion which is obtained by subtracting total demand (RM248.7 billion) with imported final use (RM42.9 billion) and imported intermediate (RM69.8 billion) components. Similar procedures are applied to the rest of the final demand components.

The imported-adjusted approach is the ideal methodology for measuring the actual performance of foreign and domestic sectors to the economy. However, our literature survey shows that this issue does not receive considerable attention in the past. To the best of our knowledge, only two countries, the Netherlands (see Kranendonk and Verbruggen, 2005) and France (see DGTPE, 2006), had attempted to measure the contribution of GDP by using this approach. Forecasting techniques and statistical measures are among the issues that receive more attention in the literature (see for example, Holz, 2014; Jiang, Guo \& Zhang, 2017).

Recently, the application of import-adjusted approach is more pronounced because of the rapid changes in international trade that demands improvement in the statistical measure (see Bank Negara Malaysia, 2013; Central Bank of Malta, 2017; Kang \& Liao, 2016). For example, "trade in value-added" or TiVA has become one of the important measures used by policy makers across the countries to trade international flows of value added embodied in trade products along the global value chain (GVC). TiVA analysis requires for expansion in the trade statistics measures that directly affects the GDP accounting methodologies. The import-adjusted approach is expected to gain interest in future because measures for GVC using multi-country supply and use table are included in the current draft of Handbook on Supply, Use and Input-Output Tables with Extensions and Applications, published by the United Nations Statistics Division (2017).

In the case of Malaysia, application of the import-adjusted approach is highly relevant because Malaysia is one of the countries that is actively involved in the GVC 
in particular for electric and electronic products. However, application of this approach is constrained by the availability of data. For example, the input-output model is used to estimate the imported intermediate content in each final demand component but the input-output table is published with lags for every five years. Similarly, data for final demand components are available annually, but at aggregated level. Taking into consideration all the data constraints, this paper provides a heuristic approach for measuring the actual contribution of foreign and domestic sectors on an annual basis. The approach that we propose here is not guaranteed to be optimal or perfect but it is sufficient to achieve satisfactory findings. We detail our approach in the next section.

\section{A Heuristic Approach}

The approach that we introduce in this paper is supported by the data that are publicly available. Our aim is to provide a practical approach that reduces man-hours for data development while obtaining satisfactory findings. Table 3 presents the data types and estimation procedures that are necessary to apply the import-adjusted approach. Figure 2 summarises estimation procedures that can be divided into three main steps.

Table 3. Data types and estimation procedures

\begin{tabular}{|c|c|c|c|c|}
\hline \multirow{2}{*}{$\begin{array}{l}\text { Final demand } \\
\text { components }\end{array}$} & \multirow{2}{*}{$\begin{array}{l}\text { Level of } \\
\text { aggregation }\end{array}$} & \multicolumn{3}{|c|}{ Separation between domestics and imports } \\
\hline & & Domestics & Final imports & Intermediate imports \\
\hline (1) & $(2)$ & (3) & (4) & (5) \\
\hline $\begin{array}{l}\text { Private } \\
\text { consumption }\end{array}$ & $\begin{array}{l}\text { Aggregated/limited } \\
\text { disaggregation }\end{array}$ & Residual & BEC & $\begin{array}{l}\text { Cannot be } \\
\text { determined }\end{array}$ \\
\hline $\begin{array}{l}\text { Government } \\
\text { consumption }\end{array}$ & $\begin{array}{l}\text { Aggregated/limited } \\
\text { disaggregation }\end{array}$ & Residual & $\mathrm{BEC}$ & $\begin{array}{l}\text { Cannot be } \\
\text { determined }\end{array}$ \\
\hline Investment & $\begin{array}{l}\text { Aggregated/limited } \\
\text { disaggregation }\end{array}$ & Residual & BEC & $\begin{array}{l}\text { Cannot be } \\
\text { determined }\end{array}$ \\
\hline Exports & $\begin{array}{l}\text { Detailed by } \\
\text { commodities }\end{array}$ & $\begin{array}{l}\text { Harmonised } \\
\text { SITC-MSIC }\end{array}$ & $\begin{array}{l}\text { Harmonised } \\
\text { SITC-MSIC }\end{array}$ & $\begin{array}{l}\text { Estimated by } \\
\text { input-output model }\end{array}$ \\
\hline
\end{tabular}

Step 1 separates total imports into imported intermediate and final use goods. Data for total imports are provided in the national accounts statistics but separation between imported intermediate and final use goods is not available. Import statistics by products are available and separation between the imported intermediate and final use goods can be estimated by applying the Broad Economic Categories (BEC) coding system (see United Nations Statistics Division, 2002 - Classifications by Broad Economic Categories). ${ }^{2}$

2 BEC coding system is the standard procedure used by national statistics office of all countries when separating imports into final and intermediate goods. Estimation of World Input-Output Database (WIOD) also applies a similar procedure (see for example Dietzenbacher, Los, Stehrer, Timmer, \& de Vries, 2013). 


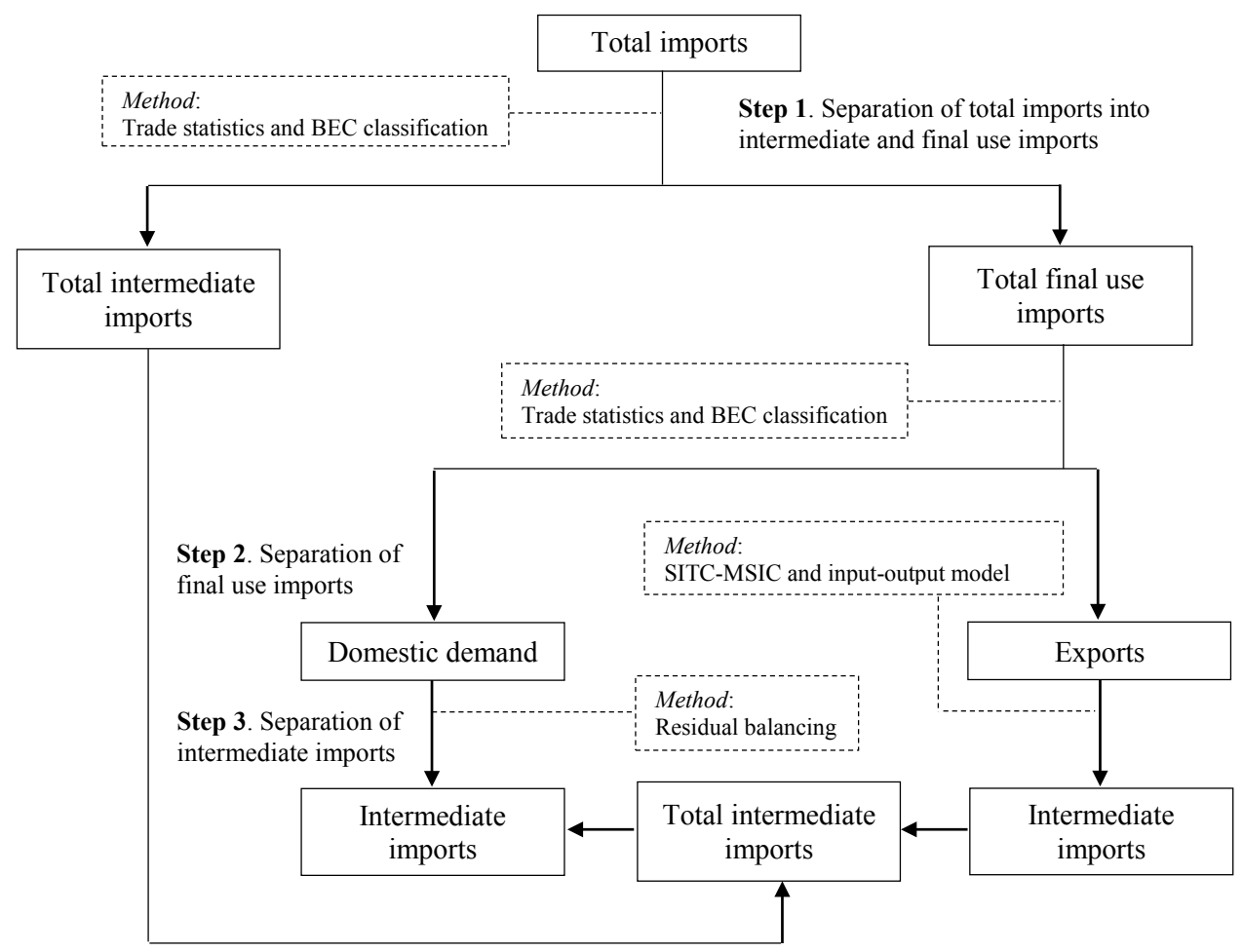

Figure 2. Separation of imports by final demand components

The next step is to estimate imported final use goods consumed by final demand components. Data for all the four final demand components at aggregated levels are available in the national accounts statistics (see for example, Department of Statistics Malaysia, 2014a). Then, the aggregated consumption by each final demand component needs to be separated between consumption on domestically produced goods and consumption on imported goods. The easiest way to separate them is by first estimating consumption on imported goods and then consumption on domestically produced goods can be obtained residually by taking the difference between total consumption and consumption on imported goods. Estimation of consumption on imported goods is performed by applying the BEC coding system. From the total imported final use, the BEC coding system is also able to further differentiate the final use imports that are attributed to private consumption, government consumption and investment.

Finally, Step 3 estimates imported intermediate goods content in the consumption on domestically produced goods. These imported intermediate goods are the raw materials and services required in the production of domestic goods. To estimate the imported intermediate goods content in private consumption, government consumption and investment components, we need detailed breakdowns of goods for the three final demand components. Although recent data published by the Department of 
Statistics Malaysia provide several breakdowns for private consumption, government consumption and investment, they cannot support the aggregation of sectors in the input-output table. For example, data for the private consumption are disaggregated according to 15 consumption categories such as food and non-alcoholic beverages, clothing and footwear, and health. However, these consumption categories are grouped not based on an ideal sectoral classification. For example, food and non-alcoholic beverages consist of not only primary agricultural products but also processed agricultural products. Primary agricultural products and processed agricultural products are two different sectoral classifications in the input-output table and associated with different input mix. For gross fixed capital formation (i.e., investment component), distinctions are made according to three broad categories: (i) structure, (ii) machinery and equipment, and (iii) other assets. Altogether, we are unable to breakdown the aggregate private consumption, government consumption and investment according to the sectors. To be useful for future studies, the private consumption, government consumption and investment components should be detailed by using the sectoralbased classification.

The most extensive data for sectoral breakdown are exports, which are detailed by various goods that are classified according to the Standard International Trade Classification (SITC). The Department of Statistics Malaysia is also able to determine exports into normal exports and re-exports. Because sectors in the input-output tables are grouped according to the Malaysia Standard Industrial Classification (MSIC, Department of Statistics Malaysia, 2008), the trade data must be harmonised. Once exports are harmonised at the individual sector, we run equation (6) to obtain the imported intermediate goods that are embodied in exports. Once imported intermediate goods required for exports are determined and provided that the total imported intermediate imports are known, the imported intermediate goods content in domestic final demand components can be obtained residually.

In harmonising the SITC trade data to MSIC, several stages have to be followed. First, the SITC undergoes the conversion process to Harmonized System (HS) codes. The HS coding system is a standard international classification system of traded goods developed by the World Customs Organization. Once the SITC has been converted into HS codes, the next step is to transform it into the MSIC by means of the Malaysia Classification by Product Activities (MCPA). The MSIC coding system classifies the goods that are exported and imported by each sector in the input-output framework. ${ }^{3}$ The conversion of exports is straightforward compared to the conversion of imports. For imports, once the commodities have been transformed from the SITC to HS codes, the next step is to classify the HS codes into intermediate goods and final use goods by using the BEC coding system. Finally, the imported intermediate goods and final use goods are assigned according to the respective sectors by using the MSIC.

It is important to note that in this paper we provide estimates for the imported intermediate goods content in total domestic final demand components. Further breakdown of imported intermediate goods content in each final demand component

3 The full harmonisation schemes may be provided upon request from authors. 
is constrained by the availability of data. One may use the assumption of fixed consumption structure for domestic demand components in the benchmark inputoutput table to estimate the imported intermediate contents. We do not use this assumption for two main reasons: (i) because it is hard to validate the assumption in the case of data limitation, and (ii) because we prefer to use actual data that can be observed directly.

\section{Results and Discussion}

Discussion of the main findings is divided into two sub-sections. Section 4.1 presents the relative contribution of net exports and domestic demands for the period 20102014 that is derived by the import-adjusted and conventional approaches. Section 4.2 provides estimation errors that aims to validate our approach.

\subsection{Relative Contribution of Net Exports}

Three major datasets are used to run our analysis. First, the latest input-output table for 2010 benchmark year is used to run equation (6). This input-output table has 124 sectoral breakdowns which are classified according to the latest Malaysia Standard Industrial Classification (Department of Statistics Malaysia, 2014b). Second, annual GDP by types of expenditures are compiled to the latest period of 2014. Third, import and export statistics by commodities which have been harmonised between SITC and MSIC. Taking into consideration the latest benchmark for the input-output table and the latest annual GDP by types of expenditures, we have estimated the contribution of domestic demands and exports to GDP for the periods 2010-2014.

Results of our analysis are presented in Table 4. Panel A in Table 4 shows the total consumption for two final demand components: domestic demands (summation of private consumption, government consumption and investment) and exports. For each final demand component, we estimate consumption on imports that is separated into imported intermediate goods and final use goods. Recall that the consumption on imported final use is determined based on the BEC coding system. The consumption of imported intermediate goods for exports is estimated based on equation (6) while that of the domestic demand is estimated residually, provided the total imported intermediate goods are known.

Panel B presents the contribution of domestic demands and exports to GDP in monetary values while Panel $C$ expresses the contribution in percentage form. Results in Panel $\mathrm{C}$ shows that the contribution of exports to GDP is decreasing. The contribution of exports was reduced by 9 percent from 42.69 percent in 2010 to 33.69 percent in 2014. There are two main explanations for the decreasing trend in the contribution of exports to GDP. First, we observe the growth of total domestic demands is larger than that of exports. Between 2010 and 2014, domestic demands expanded at an average growth rate of 8.25 percent compared to only 2.73 percent in the average annual growth rate for exports. Second, the component of imported final use consumed by exports (in national accounts imported final use is also known as re-exports) is not only large but also shows increasing trends, accelerating at an average growth rate of 22.69 
Table 4. Contribution to GDP by import-adjusted approach (RM billion, current prices)

\begin{tabular}{|c|c|c|c|c|c|c|}
\hline & & 2010 & 2011 & 2012 & 2013 & 2014 \\
\hline \multicolumn{7}{|l|}{ A. Domestic and foreign demands } \\
\hline Domestic demands & $(1)$ & 682.88 & 760.58 & 863.02 & 937.39 & $1,015.05$ \\
\hline $\begin{array}{l}\text { Consumption on imported } \\
\text { final use goods }\end{array}$ & $(2)$ & 135.83 & 152.62 & 174.22 & 176.23 & 177.50 \\
\hline $\begin{array}{l}\text { Consumption on imported } \\
\text { intermediate goods }\end{array}$ & (3) & 80.74 & 98.85 & 99.94 & 94.12 & 96.64 \\
\hline Exports & (4) & 714.08 & 777.30 & 770.20 & 770.37 & 817.18 \\
\hline $\begin{array}{l}\text { Consumption on imported } \\
\text { final use goods (re-exports) }\end{array}$ & (5) & 35.66 & 45.55 & 65.72 & 92.00 & 99.12 \\
\hline $\begin{array}{l}\text { Consumption on imported } \\
\text { intermediate goods }\end{array}$ & (6) & 331.11 & 338.29 & 325.83 & 321.06 & 341.70 \\
\hline \multicolumn{7}{|l|}{ B. Relative contribution to GDP } \\
\hline Domestic demands $(1)-[(2)+(3)]$ & (7) & 466.32 & 509.11 & 588.86 & 667.04 & 740.91 \\
\hline Exports $=(4)-[(5)+(6)]$ & (8) & 347.31 & 393.46 & 378.65 & 357.31 & 376.37 \\
\hline Total GDP $=(7)+(8)$ & (9) & 813.62 & 902.57 & 967.51 & $1,024.35$ & $1,117.28$ \\
\hline \multicolumn{7}{|l|}{ C. Relative contribution to GDP (\%) } \\
\hline Domestic demands & (10) & 57.31 & 56.41 & 60.86 & 65.12 & 66.31 \\
\hline Exports & $(11)$ & 42.69 & 43.59 & 39.14 & 34.88 & 33.69 \\
\hline \multicolumn{7}{|c|}{ D. Relative contribution to GDP (\%) - conventional approach } \\
\hline Domestic demands & $(12)$ & 83.93 & 84.27 & 89.20 & 91.51 & 90.85 \\
\hline Exports & (13) & 16.07 & 15.73 & 10.80 & 8.49 & 9.15 \\
\hline
\end{tabular}

Source: Calculated from the model.

percent between 2010 and 2014. Re-export products refer to goods that are imported and then re-exported again without change in form or substance of the products as defined by the Department of Statistics Malaysia. Under the current system of national accounts, the packaging, re-bulking and grading are not considered as changing the form of the products.

Rapid expansion in processing trade activities especially for electronic and electrical products - electronic processors, controllers, semi-conductors and other electrical components and petroleum refinery products - petroleum, fuel and gas and oil-related products contributed significantly to the share of re-export products. We observe that between 2010 and 2014, re-exports of these two major products has increased about 37.4 percent per annum for electronic and electrical products and 73.7 percent for petroleum refinery products. To be precise, export values of these two products have increased from RM7.99 billion in 2010 to RM28.47 billion in 2014 for electronic and electrical products, and from RM3.94 billion to RM35.86 billion for petroleum refinery products. As a consequence of this, shares of these two products to total re-exports increased from 33 percent in 2010 to 65 percent in 2014. The nature of processing 
trade activities encourages imports for export activities in which only slight processes of packaging and assembling are performed before the products are exported to the foreign counterparts. The increment can be explained by the active participation of processing trade activities in free zones.

We also provide the contribution of the two final demand components to GDP calculated by means of the conventional approach in Panel D. Comparing results in Panel $C$ and Panel D provides a clear indication of the bias of the conventional approach in explaining the contribution of foreign demand or trade sector. It tends to underestimate the contribution of trade while overestimating the contribution of the domestic sector. Thus, results for the import-adjusted approach (Panel C) provide a better explanation to the actual performance of domestic and trade sectors to the Malaysian economy.

\subsection{Sensitivity Analysis}

Application of the import-adjusted approach for time-series data provided in this paper deals with a large database. Although our methodologies are in line with international practices, results may be sensitive due to several estimation errors. It is important to note that the import-adjusted approach provided in this paper is essentially an extension of the input-output model. Thus, it is common in input-output literature that the benchmark input-output table is used as a comparison for validating the estimation of results (fact is that the benchmark input-output table reflects the "true" economic structure because it is derived based on economic census).

To evaluate our estimation, we compare results of our approach in 2010 with the one that is derived from the benchmark input-output table and find that our results are very close. Recall that results for 2010 are not derived directly from the benchmark input-output table but estimated based on our methodologies explained in Section 3. Specifically, our approach shows that the contribution of exports to GDP in 2010 is 42.69 percent while the calculation from the benchmark input-output table indicates 48.27 percent - deviating by only 5.58 percent. Statistically, this estimation error is acceptable and even far lower than the estimation from using the conventional approach which deviated by 32.2 percent (Panel D shows contribution of exports to GDP is 16.07 percent).

There are two technical aspects of our modelling which contributed to the errors. The first technical aspect is related to the application of fixed input-output coefficient (matrix A) and fixed import coefficient (matrix $h$ ). These two matrices are formed in equation (6) to estimate the imported intermediate goods content in exports for the period 2010-2014. The second technical aspect is related to the harmonisation procedures for matching between SITC and MSIC coding systems. Therefore, sensitivity analysis concerning the fixed input-output coefficient and import coefficient, and harmonisation procedures must be provided to verify our results.

For verification of the input-output and import coefficients, we have compared these two structural matrices between 2005 and 2010 benchmark tables. In inputoutput literature, several measures have been developed to evaluate the closeness 
of the two structural matrices, whereby the mean absolute deviation (MAD) and dissimilarity index (DI) are widely used (see for example, Miller \& Blair, 2009; Saari, Hassan, Daaniyall, \& Mohamed, 2014). For MAD and DI, the closer the value is to zero, the more highly stable the coefficients and better results can be obtained. For the inputoutput coefficient matrix, the MAD and DI statistics are 0.0049 and 0.0001 , respectively, while for the import coefficient matrix, the statistics are 0.0716 and 0.1689 . Results show a clear indication of the stability of these two structural matrices and thus the use of 2010 input-output table for the estimation of imported intermediate goods content for the next five-year period is acceptable. More importantly, the errors of prediction could be further reduced if working with the highly aggregated input-output table (see Saari et al., 2014).

Harmonisation procedures for SITC-MSIC coding systems are applied for both imports and exports. The Department of Statistics Malaysia has published the latest Malaysia Classification of Products by Activity (MCPA) 2009 that contains an extensive list of all products by economic activity in Malaysia (see Department of Statistics Malaysia, 2010b). The MCPA serves as the main reference for matching between SITC and MSIC classifications. For verification of our harmonisation procedures, we have compared the export and import values derived from the SITC-MSIC matching for 2010 with the ones available in the benchmark input-output table. The comparison is done by using the sum squared error (SSE) and standard error (SE) that are commonly used to measure variability in time series data (Oberuc, 2004). If in all cases the harmonised data are identical to the benchmark data, both SSE and SE would be equal to O. MAD and DI measures are not very relevant in this case because they required a large number of cells or observations which is usually observed in the input-output table. Results for the estimated SSE and SE of exports are 0.0375 and 0.0075 ; meanwhile, the SSE and SE of imports are 0.0518 and 0.0085 respectively. This clearly shows that the harmonised data are highly reliable and can be utilised for further analysis. In addition to SSE and SE, we also tabulate the distribution of exports and imports taken from the benchmark input-output table that is derived from our estimation. Results indicate that the two distributions are very close with correlation coefficients of 0.88 for exports and 0.80 for imports. ${ }^{4}$

Sensitivity analysis indicates that the two input-output coefficients (matrices $\mathbf{A}$ and $\mathbf{h}$ ) and harmonisation procedures are not considered to be perfect estimators. There are several ways to improve accuracy of input-output coefficients. One may, for example, introduce non-linear import coefficients by estimating import-output elasticities. However, data which are necessary for the estimation of elasticities are limited because the number of sectors in input-output table are large. Application of time-series input-output tables is a great option but the tables are not available in Malaysia. Harmonisation errors during the matching processes between different classifications are expected to occur but no standardise classifications are available publicly for comparison.

4 Correlation coefficient illustrates a quantitative measure of degree association between two variables. It ranges from 0 for perfectly having no association to 1 for perfectly having association. 


\section{Concluding Remarks}

This paper introduces a heuristic approach in measuring the contribution of foreign trade (or exports) on the Malaysian economy. We have shown that given a benchmark input-output table and provided with the annual trade statistics, the bias in measuring the contribution of domestic demands and exports can be reduced. More importantly, we have provided a practical approach that does not only reduce man-hours required for database development but also obtain satisfactory findings.

There are two advantages of our approach to policy makers. First, we have provided the actual performance and contribution of domestic demands and exports to Malaysian GDP growth. The conventional approach tends to overestimate the contribution of domestic demands and underestimate the contribution of exports. As a result, the conventional approach is likely to provide bias regarding the sources of growth in the economy. Second, our approach is able to provide a better explanation to the growth of certain final demand components. For example, we have explained that the declining contribution of exports to the Malaysian economy is driven by offshoring trade activities. These explanations cannot be found in the conventional approach because it is too simplistic and unable to provide a meaningful analysis for the sources of growth.

\section{References}

Bank Negara Malaysia. (2013). BNM annual report 2012. Kuala Lumpur: Percetakan Nasional Berhad.

Central Bank of Malta. (2017). Forty-ninth annual report and statement of accounts 2016. Malta: Author.

Department of Statistics Malaysia. (2008). Malaysia standard industrial classification 2008. Putrajaya: Author.

Department of Statistics Malaysia. (2010a). Input-output tables Malaysia 2005. Putrajaya: Author.

Department of Statistics Malaysia. (2010b). Malaysia classification of products by activity 2009. Putrajaya: Author.

Department of Statistics Malaysia. (2014a). Annual gross domestic product 2005-2013. Putrajaya: Author.

Department of Statistics Malaysia. (2014b). Input-output tables Malaysia 2010. Putrajaya: Author.

Dietzenbacher, E., Los, B., Stehrer, R., Timmer, P., \& de Vries, G. (2013). The construction of world input-output tables in the WIOD project. Economic Systems Research, 25(1), 71-98. https:// doi.org/10.1080/09535314.2012.761180

Direction Générale du Trésor et de la Politique Economique (DGTPE). (2006). Reinterpreting the contribution of foreign trade to growth. Trésor-Economics, 6(December), 1-7.

Holz, C.A. (2014). The quality of China's GDP statistics. China Economic Review, 30(September), 309-338. https://doi.org/10.1016/j.chieco.2014.06.009

Jiang, Y., Guo, Y., \& Zhang, Y. (2017). Forecasting China's GDP growth using dynamic factors and mixed-frequency data. Economic Modelling, 66(November), 132-138. https://doi. org/10.1016/j.econmod.2017.06.005

Kang, J.S., \& Liao, W. (2016). Chinese imports: What's behind the slowdown? (International Monetary Fund Working Paper No. WP/16/106). Washington, DC: International Monetary Fund. 
Kranendonk, H.C., \& Verbruggen, J.P. (2005). How to determine the contributions of domestic demand and exports to economic growth? Dutch versus international method (CPB Memorandum 129). The Hague, Netherlands: CPB Netherlands Bureau of Policy Analysis.

Miller, R.E., \& Blair, P.D. (2009). Input-output Analysis: Foundations and extensions. Cambridge, UK: Cambridge University Press:.

Oberuc, R.E. (2004). Dynamic portfolio theory and management: Using active asset allocation to improve profits and reduce risk. New York, NY: Mc-Graw Hill.

Saari, M.Y., Hassan, A., Daaniyall, M.A.R., \& Mohamed, A. (2014). Evaluation of the relative performance of RAS and cross-entropy techniques for updating input-output tables for Malaysia. Malaysian Journal of Economic Studies, 51(2), 217-229.

United Nations Statistics Division. (2002). Classifications by broad economic categories. New York, NY: Author.

United Nations Statistics Division. (2017). Handbook on supply, use and input-output tables with extensions and applications. New York, NY: Author. Retrieved from https://unstats.un.org/ unsd/nationalaccount/consultationDocs/Handbook_IO_draft.pdf 
